\title{
Para uma Abordagem Global dos Problemas de Pessoal na Administração Pública (*)
}

\section{Georges LANGROD}

\author{
Directeur Scientifique au C NRS \\ (Centro Nacional de Pesquisa Cientifica - \\ Paris, França)
}

\section{Tradução de ARAÚJO CAVALCANTI}

Fonte: International Review of Administrative Sciences. Révue Internationale des Sciences Administratives. Vol. XXXVII, n. ${ }^{\circ}$ 3, 1971. I I A S, Brussels.

OBSERVAÇõES: As tendências gerais da administração pública de amanhã - especificamente nesta turbulenta década dos anos 70 - constituem um dos temas favoritos dos arúspices da futurologia.

Nos paises desenvolvidos o assunto - realmente fascinante - tem sido objeto de uma verdadeira explosão bibliográfica: livros, relatórios especiais, Conferências, seminários, artigos, polêmicas, pesquisas e análises de toda ordem surgem diariamente, notadamen-

no cenário das universidades, con-

0 artigo a seguir publicado integra o relatado que, sob o mesmo titulo, foi apresenNew pelo prof. Georges Langrod, em

dew York, no desempenho de uma missẵo

da consulta $\theta$ assisténcia técnica, na sede

de ONU, no perlodo de 19 de dezembro

(C D 1969 a 19 de Janeiro de 1970 -

(C D U 35.08). vergindo para o estudo e avaliação critica da natureza, conteúdo, alcance e evoluçăo dos complexos problemas situados nesse universo cinzento, tão propicio aos devaneios das utopias ingênuas como às agourentas alucinações dos profetas do apocalipse termonuclear. Não importa: o fenômeno em si representa uma daquelas mencionadas tendências que, aos poucos, vem se irradiando $\theta$ materializando com poderoso impacto na vida quotidiana, em todas as latitudes do planeta $e$, quiçá, no mais intimo recôndito da consciência de cada ser humano.

Numa tentativa de sintese, o Diretor da Divisăo de Administraçăo Pública das Naçőes Unidas, Prof. Chi-Yuen-WU, ao ensejo da Conferência que, sobre o assunto, a American Society of Public 
Administration promoveu, em Denver, USA., a 19 de abril de 1971, logrou condensar as aludidas tendências em 10 grupos principais, advertindo, contudo, haver excluido muitas outras pela impossibilidade de esgotar a matéria nos limites preestabelecidos da Conferência de Denver.

São as seguintes, na opinião daquele eminente Diretor da ONU, as caracteristicas da administração pública nos próximos 10 anos:

1) A administração continuará crescendo em volume e importância na totalidade dos países.

2) A administração tornar-se-á cada vez mais complexa a fim de que os governos possam enfrentar problemas adicionais de toda ordem.

3) As exigências da planificação, do controle e da coordenação tornarse-ão preponderantes em face das novas dimensões e sofisticação tecnológica dos sistemas administrativos que substituirão os mecanismos tradicionais de governo e administração peremptos e incapazes de enfrentar os desafios de um mundo gradualmente cibernetizado.

4) A administração tornar-se-á cada vez mais sensivel à ambiência política e às pressões do ecosistema num contexto global de valorização $\theta$ fortalecimento do poder executivo, dos administradores e e dos empresários superiormente qualificados.

R. Serv. públ., Brasília, 108 (3) set./dez. 1973
5) As abordagens racionais, quantitativas e sistêmicas dominarăo os cenários da administração $e$ das empresas nas quais os computadores $e$ a instrumentalidade eletrônica em geral, desempenharão papéis decisivos.

6) Os estilos de administração voltados para a eficiência e a produtividade estimularão, todavia, uma utilização cada vez maior dos postulados e técnicas da psico-sociologia a fim de evitar a robotização e desumanização dos serviços públicos e dos seus agentes.

7) A participação das populações aumentará significativamente no tocante às decisões a serem tomadas nos domínios do bem-estar, do desenvolvimento planificado $e$ da justiça social, paralelamente ao crescimento da periculosidade decorrente da poluição ambiental, da explosão demográfica, da exaustão dos recursos naturais $\theta$ problemas correlatos.

8) A aceleração do ritmo das transformações científicas e tecnológicas provocará, nos parâmetros da administração, um processo de profundas repercussões atingindo, igualmente, homens, estratégias, métodos, equipamentos $e$ assim por diante.

9) A modernização permanente $e$ a melhoria dos padrões de "qualidade da vida" passarão a constituir uma verdadeira obsessăo dos governos, instituições, em- 
presas, organizações e indivíduos responsáveis em todos os países.

10) Em conseqüência, a "Politica de Pessoal" concebida como mobilização de recursos humanos altamente qualificados e rigorosamente selecionados, apresentará novas e revolucionárias dimensões. Os problemas da administração de pessoal, na multiplicidade de seus aspectos, tornarse-ão inexoravelmente prioritátários.

(Cf. Public Administration in the 1970 's, by Chi-Yuen-WU, in Revue Internationale des Sciences Administratives, v. 37, n. $^{\circ} 3,1971$, Brussels, pp. 161/175).

As considerações acima bastam para acentuar a oportunidade e importância do trabalho ora divulgado pela "Revista do Serviço Público", de autoria do Prof. Georges LANGROD, do Centro Nacional de Pesquisas Científicas, da França, sediado em Paris: PARA UMA ABORDAGEM GLOBAL DOS PROBLEMAS DE PESSOAL NA ADMINISTRAÇÃO PÚBLICA. O conteúdo dessa autorizada contribuição ao estudo da moderna administraçăo de pessoal pode ser condensados nos seguintes tópicos:

I - Politica de Pessoal (Esclarecimento preliminar. Conceituação, trafos característicos, razões de ser. Objetivos. Vantagens e desvantagens do sistema de carreiras: aspectos básicos. Mercado de trabalho. Informa̧̧ăo. Formação. Polivalência. Participaçào. Personalidade dos funcionários. Elementos de uma "politique de carrière". Seleção, recrutamento, admis- são, nomeação; tipos de aperfeiçoamento. Cadastramento, registros, movimentação. Promoção. Remuneração. Responsabilidade disciplinar. Vantagens Sociais. Aposentadoria.).

II - Meios institucionais da Administração de Pessoal. Generalidades. Coleta e armazenamento de dados. Técnicas. Órgãos. III - Notas.

\section{Introdução}

A idéia de uma abordagem global antídoto contra as deformações do unilateralismo no tratamento dos problemas, - no caso específico de uma política de pessoal teria forçosamente de ocorrer no instante da concepção, planejamento e elaboração dos meios de desenvolvimento dos recursos humanos. Com efeito, uma administração de pessoal concedida nestes termos vincula-se, prioritariamente, à eficácia do sistema administrativo como uma de suas componentes básicas, incorporando-se, ao mesmo tempo, ao elenco das responsabilidades primordiais do Estado no concernente à captação, aperfeiçoamento, mobilização e valorização dos recursos humanos, sem os quais os governos ficariam impossibilitados de atuar e o próprio Estado seria apenas uma custosa abstração jurídica ou, na hipótese mais provável, uma ameaçadora máquina burocrática.

Convém sublinhar que na maioria dos paises, notadamente os não industrializados, aquela mencionada responsabilidade primordial do Estado ou seja, uma politica de pessoal para o desenvolvimento - resulta, também, de uma situação concreta: é que a denominada "fonction publique" dos fran- 
ceses, isto é, a massa constituida pelo funcionalismo público no exercício de cargos, funções, empregos, de enorme variedade, ocupa um lugar preponderante no mercado de trabalho no qual repercutem as medidas de politica administrativa adotada, acarretando repercussões de toda ordem nas esferas econômica e social.

O Estado se vê, desta forma, compelido a exercer os poderes de que dispõe tendo em vista o máximo rendimento dos contingentes humanos a seu serviço, pelos menores custos possíveis, empregando o manpower disponivel nos parâmetros e diretrizes de uma política de pessoal orientada no sentido da racionalidade e da eficiência operacional. Nestas condições, a administração de pessoal exerce uma influência positiva, estimulante e fortalecedora do mercado de trabalho.

Evidentemente, a colimada produtividade de uma politica de pessoal que se possa traduzir, na prática, em realizações, iniciativas e atos concretos de desenvolvimento dos recursos humanos tem, como fator condicionante, - pressuposto da formação cultural, técnica e profissional da totalidade dos funcionários engajados nos serviços públicos. Acima de tudo, trata-se de descobrir, mobilizar, estimular e conservar as melhores competências, aptidões, talentos e conhecimentos, sem o que não poderá o Estado enfrentar os problemas e necessidades do Pais, circunscrever e reduzir o desperdicio dos recursos. A variedade, mutabilidade e complexidade dos objetivos a serem atingidos exigem e Justificam, por conseguinte, uma tentativa de abordagem global dos problemas de pessoal na R. Serv. públ., Brasília, 108 (3) set./dez. 1973 administração pública, tal como preconizada nesta exposição. $O$ documento pretende levar a efeito uma análise abrangente deste enfoque. Os conceitos subjacentes e as idéias principais são esmiuçadas, principalmente a noção de carreira e seu adequado desenvolvimento que o documento considera como o eixo em torno do qual deve ser organizada uma política de pessoal, cuja expressão objetiva se concretiza numa administração de pessoal coerente e dinâmica. $O$ relatório em questão examina, de preferência, a administração dos Estados nos quais a função pública tem como fundamento o princípio da continuidade do serviço. Contudo, também cogita dos problemas que todos os países em desenvolvimento têm de enfrentar, nessa área, e cuja solução desafia a capacidade administrativa dos respectivos go. vernos.

A planificação do desenvolvimento das carreiras, examinada em funçāo da ótica ora preconizada, reflete a interdependência que deve existir entre as sucessivas etapas de uma mesma carreira e o entrosamento dos elementos componentes de um coerente sistema de carreiras profissionais. Por outro lado, o planejamento das carrelras evidencia a natureza de uma abordagem dinâmica dos problemas implicitos na administração de pessoal, ao enfatizar a necessidade de uma eficaz distribuição dos efetivos, constante adaptação e permanente desenvolvimento dos recursos humanos na administração.

\section{Politica de Pessoal}

Não há como ignorar e pôr em dúvida que a ausência de uma verdadeira 
política de pessoal avulta, talvez, como um dos principais fatores do mau emprego ou deficiente utilização das potencialidades humanas nos serviços públicos. A experiência de muitos países comprova-o sobejamente. Impõe-se, todavia, para melhor esclarecer o assunto, algumas considerações adicionais sobre o tema e seus traços caracteristicos.

a) Esclarecimentos. A política de pessoal aparece como um conjunto de medidas escalonadas no tempo, desencadeadas nos parâmetros de uma doutrina única de que emanam, abordadas, no entanto, pelo prisma de uma ótica uniforme, a longo ou médio prazos. Vinculada ao conjunto englobado pelos efetivos da função pública, a referida política, independentemente de suas peculiaridades estatutárias, abrange todas as etapas do serviço a que se aplica, no decorrer de sua duração.

\section{b) Traços caracteristicos:}

I) Uma politica global concebida de maneira correta é empírica e estática ao enfrentar casos ou problemas rotineiros imediatos; mas, sobretudo, dinâmica, quando procura assegurar um Permanente e harmonioso desenvolvimento dos recursos humanos no âmbito da administração de pessoal. Nesto caso, ela se dimensiona como uma Verdadeira política de mão-de-obra cujas repercussões - diretas e indiretas - se exercem sobre toda a administração pública, na plenitude de seus efeitos.

A ausência, no passado, de uma politica de pessoal com essas dimensões - características é facilmente explicá- vel pela inexistência de informações exatas e conseqüente desconhecimento das condições do mercado de trabalho.

A precariedade e as deficiências resultantes dessa situação contribuíram para o esvaziamento e a frustração de diversas experiências isoladas de reformas, geralmente setoriais e fragmentárias. Nos paises em desenvolvimento as tentativas reformadoras esbarravam diante de enormes dificuldades em face da escassez de mão-de-obra qualificada.

II) A adoção de uma política abrangente de pessoal na Administração Pública promove uma distribuição mais adequada e equitativa dos recursos humanos disponíveis. Além disso, uma abordagem global enseja o tratamento realista dos problemas pelo melhor conhecimento das condições e necessidades dos diferentes serviços (centrais, regionais e locais).

Esta distribuição dos efetivos por meio de nomeações, designações ou admissões planificadas, além de corresponder aos objetivos gerais do sistema administrativo em que se integram os serviços públicos, é levada a efeito de acordo com certas regras preestabelecidas. A observação das aludidas regras, diretrizes e normas decorre dos imperativos estabelecidos pelos princípios abstratos da legalidade formal de natureza ética e juridica, imperativos aos quais se acrescentam exigências de ordem técnica ou administrativa imprescindiveis ao funcionamento satisfatório do sistema administrativo global, como, obviamen- 
te, a necessidade de assegurar uma racional distribuição do pessoal.

III) Uma visão de conjunto ou abordagem global dos problemas de pessoal na Administração Pública - (que já foi, aliás, objeto de um plano geral elaborado pelo Professor Chi-Yuen-WU, Diretor da Divisão de Administração Pública da ONU, em um ensaio específico sobre o assunto) - depende, do ponto de vista de sua exeqüibilidade, do fator tempo, da relativa continuidade do serviço e de um criterioso planejamento. $O$ planejamento e a elaboração de uma política desse tipo constitui um autêntico desafio a ser enfrentado.

A abordagem do serviço administrativo sob o ângulo de um processo dinâmico, composto de sucessivos estágios estreitamente interligados e entrosados, em virtude de uma concepção abrangente de unidade e continuidade, adquire as proporções de uma legítima estratégia. Eliminam-se a anarquia e o acaso na disposição dos efetivos, ao mesmo tempo em que se rompe com a tradição das medidas fragmentadas, limitadas a certos estágios isolados do serviço e ditadas pela pressão dos acontecimentos ou por considerações irracionais. Esta concepção se adapta e se enquadra, até certo ponto, em todos os sistemas administrativos (Cf. Os serviços centrais da função pública nos países em desenvolvimento. Nações Unidas, New York, 1968, p. 11).

IV) A concepção de uma politica integrada para a função pública, embasamento e cerne dos sistemas administrativos, - proporciona condi- ções de viabilidade ao planejamento das carreiras no quadro lógico e cronológico de um desenvolvimento equilibrado. No bojo da "macro-política" integrada de pessoal, a elaboração, estruturação e ordenamento das carreiras desempenham o papel de uma "micropolitica" ou seja, a projeção no plano individual do funcionário da "macropolítica" de pessoal. São dois enfoques que se complementam para uma abordagem realista de problemas idênticos ou semelhantes, examinados sob dois angulos diferentes. A atuaçăo $e$ os serviços dos funcionários na concepção da "carrière" (1) não mais comportam traços do misticismo que, durante muito tempo, na história administrativa de paises europeus, - como reminiscência da época colonial, caracterizou os vínculos dos funcioná. rios com o Estado. No sistema das carreiras o papel desempenhado e os serviços prestados pelos funcionários adquiriram caráter profissional, à semelhança de determinados empregos do setor privado com os quais se podiam comparar, apesar do estigma característico do serviço público.

Quando o Estado é freqüentemente o único empresário ou, talvez, o mais importante do mercado, como acontece em alguns países subdesenvolvidos, não é nada fácil atrair candidatos válidos para os cargos ou funções públicas e neles conservá-los. A instabilidade e a falta de continuidade no funcionamento regular dos seriços, entre outros motivos, são fatores que dificultam a obtençăo de candidatos válidos. Conseqüentemente, afigura-se indispensável criar e fortalecer, na medida do possivel, vínculos inteiramente destituídos de quaisquer elementos ou 
conotações misticas, porquanto, a partir do advento das carreiras predomina e se expande a profissionalização. A natureza profissional da "carrière" valoriza determinados aspectos ou dados como, por exemplo, competência, continuidade e enquadramento. São valoros que identificam e vinculam o funcionário à função desempenhada, garantindo a amortização do custo social do recrutamento, da formação e do aperfeiçoamento do pessoal. É na profissionalização que se encontra, portanto, a pedra angular de uma necessária reorientação dos problemas da função pública, cujo alcance - particularmente importante para os paises em desenvolvimento - salta aos olhos.

\section{c) Razões de Ser}

A necessidade do planejamento e implantação de uma política de pessoal integrada que institua, no cerne de sua atuação, o sistema das carreiras, tem como razões de ser válidas, particularmente nos paises em desenvolvimento, as seguintes consideraçöes:

l) O Estado emprega nesses países, como o grande patrão, uma importante mão-de-obra qualificada. Nessa qualidade de grande empregador o Estado exerce poderosa e, por vezes, decisiva influência sobre o mercado de trabalho. As flutuações dos efetivos na Administração Pública provocam lacunas dificeis de preencher, por vezes obstaculizando a regularidade de funcionamento e a própria continuidade dos serviços. Ignorar ou não levar em consideraçăo as conseqüências das flutua§ōes do "manpower" equivale a criar,

(1) Ver nota n.0 1 sobre "Carreira". inconscientemente, as condições de um "contra-desenvolvimento" com todos os graves efeitos que isso comporta, daí decorrentes. 2

II) Dois traços característicos ocorrem na função pública, aparentemente contraditórios, mas, na verdade, complementares: - de um lado, a extrema variedade das categorias de empregos e correspondente diversidade das aptidões e especializações; e de outro lado, a interdependência dessas categorias que não são herméticas, nem podem ser tratadas isoladamente. Em conseqüência, toda medida referente a qualquer uma dessas categorias provoca repercussões, mais ou menos imediatas, sobre as outras. Medidas unilaterais que não levem em consideração a interdependência das mencionadas categorias correm o risco de ocasionar traumatismos ou perturbaçōes no âmbito geral de todo o sistema.

III) Sem menosprezar o papel de outras categorias de pessoal no conjunto do sistema geral (especialmente os quadros médios e o pessoal técnico), é preciso acentuar, com o devido relevo, a importância dos quadros altamente qualificados de direção $e$ assessoramento superiores, face ao significado do respectivo desempenho. Admite-se, geralmente, que a crescente importância, qualitativa e quantitativa, do pessoal dirigente (niveis superiores responsáveis pelas atribuições ou encargos de concepção, planejamento e de comando), aumentará ainda mais nos serviços públicos dos anos vindouros. Qualquer modalidade de desperdício de recursos humanos, na faixa dos niveis superiores de direção, seria altamente desastrosa pelas suas reper- 
cussões negativas, - tanto do ponto de vista da função pública como no concernente ao sistema global. No caso dos paises em desenvolvimento os efeitos seriam, talvez, ainda mais nefastos.

Uma ambiência de instabilidade administrativa é incompativel, pelos seus efeitos negativos, com a formação e desenvolvimento dos quadros de dirigentes qualificados de nivel superior, sumamente escassos no mercado de trabalho. A evasão dos talentos nessa categoria de pessoal tem de ser contida mediante providências adequadas, a fim de evitar impasses ou estrangulamentos.

A integração em uma carreira revela - grau de maturidade que a administração ou a empresa lograram atingir em virtude do estabelecimento de condiçōes favoráveis de funcionamento.

A estabilidade, a competência, o aperfeiçoamento e a motivação, em geral. neutralizam os perigos da instabilidade administrativa, a qual levada aos conhecidos exageros observados em muitos países, bloquearia a normalidade institucional e o funcionamento eficiente dos serviços públicos.

IV) Não se deve deixar de considerar, nesta ordem de idéias, a perspectiva financeira. É preciso atentar para a essencialidade dos custos de manutenção dos serviços administrativos. São ameaçadoras as repercussões dos aludidos custos, no que se refere à politica financeira dos paises em desenvolvimento, quando inexistem ou escasseiam remédios ou corretivos efica- zes contra a instabilidade, a descontinuidade e os desperdícios.

A ineficiência, a estagnação $e$ caos, - quando se menosprezam os imperativos da racionalização, - são perspectivas catastróficas para os sistemas administrativos que postergam ou deixam de tomar as necessárias providências corretivas. Dados orçamentários comparados demonstram que as despesas com o custeio do pessoal dos quadros da "fonction publique" sobrecarregam pesadamente os encargos financeiros gerais dos Estados, em quase todos os países. A seriedade do problema avulta ainda mais quando se examinam os altos custos indiretos $\mathrm{ge}^{-}$ rados pelas múltiplas e dispendiosas deficiências oriundas da baixa produtividade de um pessoal mal selecionado, mal recrutado, pouco ou nada aperfeiçoado, cujo trabalho não corresponde às exigências e padrões da época moderna.

As verdadeiras economias orçamentárias, de caráter duradouro, se vinculam e decorrem, precisamente, dos corretivos ou providências saneadoras, porventura realizadas no sentido de $e^{S^{-}}$ tancar as fontes do mal, eliminando as causas, ao invés de cuidar exclusivamente dos meros sintomas.

V) A Administração Pública são os homens e as mulheres que a compóem. "L'administration, ce sont les hommes", resumia velho e conhecido provérbio.

A importância do fator humano para o bom andamento do serviço público e eficácia das ações empreendidas, é axioma indiscutivel que não precisa de qualquer demonstração. 
Com efeito, tudo depende da personalidade dos funcionários, de sua contribuição profissional e cultural, grau de especialização, dinamismo criador, espírito pioneiro e dedicação à sua missão.

Ao contrário, a resistência às mudanÇas, incompreensão do meio e de suas necessidades, o conservadorismo esclerosado ou excessivo apego a um "legalismo" formalista, burocratizado, "paPérassier" e distanciado da vida, que Caracterizam tantos funcionários, são conhecidos, generalizados e perigosos fenômenos da patologia administrativa; são fatores negativos que obstaculizam Ou, nos casos mais graves, anulam a "mise-en-oevre", a satisfatória exeCução da política global do Estado, entendida, nesta acepção, como somatório dos planos, atividades e atuação geral dos sistemas administrativos. A exeqüilibilidade desta política, embora concretize decisões prioritárias do governo, depende, fundamentalmente, quanto à sua qualidade - do nivel da função pública, tanto vale dizer, do Pessoal que a elabora e executa. A racionalidade e eficácia das atribuifões e encargos da administração pública, tanto no seu aspecto estrutural las armaduras dos mecanismos governamentais da organização administrativa), como no tocante ao aspecto funcional (articulaçöes e procedimentos em geral), são inseparáveis de uma correta politica de pessoal, por conseguinte, também, na dependência do Planejamento e desenvolvimento regular das carreiras.

VI) Os contingentes de funcionários que, em diversas categorias e niveis So integram no conjunto geral da fun- ção pública, como núcleo de complexos sistemas administrativos, em virtude da influência que exercem nos planos cultural, sócio-econômico e politico, pouco a pouco se transformam em uma força coletiva de pressăo que não há como ignorar ou subestimar, principalmente, nos paises do chamado Terceiro Mundo. O problema, quando examinado na perspectiva de uma abordagem global da política de pessoal, sugere a existência de possibilidade de aproveitamento dessa força coletiva de pressão no interesse geral do país e de sua incorporação à vida da comunidade.

\section{d) Objetivos}

A abordagem global dos problemas de pessoal na administração pública tem como objetivos, conforme anteriormente acentuado:

1) O máximo crescimento da produtividade agregada da função pública como um todo.

II) A reduçăo, na medida do possivel, das despesas de pessoal, a fim de que o respectivo custo não ultrapasse limites razoáveis e corresponda ao planejamento estabelecido.

III) O máximo desenvolvimento da capacitação intelectual, profissional e moral dos funcionários, em todos os niveis, a fim de que a função pública seja, ao mesmo tempo, instrumento avançado do desenvolvimento nacional e do bem-estar comunitário. Destarte, os funcionários evoluiriam de uma posição de espectadores, ou de beneficiários privilegiados, para um desempenho positivo, como animadores e 
protagonistas, atuando na vanguarda da execução dos programas com um senso maior de responsabilidade social.

IV) O advento de uma nova mentalidade estimularia o Estado, no sentido de promover a reformulação das atividades de seleção e recrutamento, um maior entrosamento com o sistema educativo, científico, tecnológico e cultural do país, e o estabelecimento de pontes entre a educação geral e a formação profissional, com a finalidade de assegurar o fluxo permanente dos melhores talentos e valores disponiveis para os quadros administrativos.

V) O estancamento ou eliminação das flutuações dos recursos humanos disponiveis contribuiria para manter no serviço os elementos válidos, além de reagir contra o "brain-drain", a evasão dos talentos e capacidades para o exterior. A fuga dos melhores valores disponiveis empobrece os paises vitimas desse fenômeno, reduzindo suas possibilidades de desenvolvimento. A corrida para o setor privado, quando ocorre, é uma ameaça de esvaziamento que a Administração não pode se dar ao luxo de menosprezar.

VI) A garantia de estabilidade e segurança do emprego em função de regras estatutárias, arranjos e medidas oportunas relativas ao eficiente desenvolvimento do sistema de carreiras através de meios que possam contribuir para obtenção desses resultados.

VII) A introdução em todos os niveis, categorias e setores da função públiča, de um sistema de valores específicos para estimular a objetividade das abordagens, a adoção de padrões éticos, R. Serv. públ., Brasilia, 108 (3) set./dez. 1973 a disciplina do trabalho profissional, a continuidade e a estabilidade, a permanente adaptação às mudanças.

VIII) A execução de uma política de abordagem global, na órbita da administração de pessoal se reflete, de imediato, no adequado planejamento das carreiras. (Cf., por exemplo, os documentos da ONU E/3630 e E/3765 e "Os Serviços Centrais... op. cit., p. ${ }^{158}$ e seguintes).

\section{e) Vantagens e desvantagens}

A principal vantagem decorrente da implantação das carreiras consiste na possibilidade de introduzir e concretizar, na órbita da administração de pessoal, o "sistema do mérito" - verdadeira obsessão dos administradores responsáveis.

Com efeito, na ausência de uma política dimensionada em função da abordagem global dos problemas e, a despeito das aparências de uma "fachada" legal, traduzida no formalismo e rituais de uma suposta legalidade, as operações concernentes à gestão do pessoal, - desde a admissão do funcionário ao serviço, o desenrolar de sua carreira profissional até o encerramento de suas atividades com a aposentadoria, - ficam seriamente expostas aos perigos das interferências espúrias e abastardamento funcional, assaz conhecidas na história da função pública ("Spoils System", "Système de dépouilles", o domínio do "pistolăo"). Abre-se o caminho ao nepotismo, e ao cortejo de suas nefastas repercussóes, a partir do momento em que se marginaliza a objetividade e se implantam o empirismo e o unilateralismo no cam- 
Po da administração de pessoal. É desnecessário acrescentar que esta ameaŞa não se erradica facilmente. A fragmentação organizacional, favorecendo a desorientação, contribui para reduzir a eficiência $\theta$ aumentar 0 custo dos serviços.

Observa-se uma separação cada vez maior entre o mundo instável de nossa época, - destinado a se tornar ainda mais instável nas décadas vindouras, - e o tempo no qual ainda se arrasta a Administração. Este hiato é particularmente significativo nos países em desenvolvimento, nos quais tende a crescer a distância entre a evolução da sociedade e a lentidão do ritmo administrativo; entre a rigidez de práticas destituidas de uma doutrina de base e o desenrolar da evolução no espaço social. O conhecimento e as implicações do fenêmeno são importantes para o equacionamento de quaisquer reformas em que o fator humano sempre desempenha o papel decisivo.

Os paises em desenvolvimento nem sempre resistem à tentação de imitar os maus exemplos do passado vivido Delas nações industrializadas que atingiram seu atual nivel depois de longa - dolorosa evolução. 0 mimetismo e c. fascinio das soluções importadas não Impedem a paralisia da funçăo pública, nem estimulam o advento do Progresso no campo da administração. Dal a importância de uma abordagem global e realista dos problemas, de maneira a reformular năo somente as Carreiras como os meios e técnicas de gestão na área da administração de Pessoal. A integração desses meios atualmente dispersos deve levar em consideração as necessidades dos serviços que năo são naturalmente dinâmicos. Esta integração visa proporcionar à administração condições para realizar, com êxito, um programa operacional lógico e realista. As vantagens psicológicas deste enfoque, anteriormente mencionadas, pressupöem algumas condições a serem simultaneamente preenchidas:

I) É preciso que se esclareça e dimensione, preliminarmente, uma politica do mercado de trabalho, visando assegurar uma melhor distribuição da mão-de-obra qualificada, inclusive do pessoal administrativo.

II) Cumpre estabelecr um sistema permanente de formação do pessoal com ciclos de aperfeiçoamento adaptado aos niveis requeridos, garantindo aos funcionários um complemento à educação preliminar. Esta formaçăo deve ter o caráter de orientação profissional (vocational guidance), corretamente planificada e utilização racional ulterior no interesse do serviço, - antes de mais nada no plano da admissão decorrente de sua especialização; trata-se de um instrumento capital da política.

III) É preciso prever a existência e a permanente atuação dos órgãos incumbidos de implementar a administração do pessoal, de acordo com a política preestabelecida. Estes órgãos devem ser devidamente equipados, dispor de atribuições positivas e gozar do indispensável prestígio no seio da Administração e de sua ambiência (particularmente perante as instituições de ensino geral). 
IV) A politica de carreira deve ser flexivel abrangendo todas as categorias de funcionários, independentemente de consideraçőes legais e da forma estatutária da admissão (nomeação unilateral, permanente ou temporária; contrato bilateral); prever a possibilidade de uma certa proporção de engajamentos laterais (sobretudo para cargos de maior categoria), bem como arranjos para atender às necessidades especlficas a curto prazo, sem excluir permutas de pessoas entre os setores público, para-público e privado. As desvantagens do sistema a adotar poderiam se referir aos períodos da rigidez, do nascimento de um ambiente burocrático, mais ou menos esclerosado, do aparecimento de castas hierárquicas fechadas e elitistas, de um exagerado escalonamento vertical capaz de impedir a eficiência operacional.

Uma estabilidade mal compreendida pode conduzir ao imobilismo, além de originar atitudes passivas e estáticas. Estes graves perigos podem levar à paralisia todo o mecanismo administrativo, na hipótese em que não se acuda a tempo, e de maneira enérgica, com os necessários corretivos. A elasticidade do acesso às carreiras, a admissão da mobilidade funcional (obrigatória e periódica, se o número e qualidade dos efetivos permitirem), a ênfase colocada sobre o fator da polivalência e um certo grau de intercâmbio entre os quadros, a concepção das categorias "abertas" (passagem de uma para outra), etc., são aspectos a serem devidamente examinados.

Uma atuação contínua e dinâmica dos órgãos de administração de pes-

R. Serv. públ., Brasilia, 108 (3) set./dez. 1973 soal, sempre atentos às diretrizes preestabelecidas da politica de pessoal deve, nesse contexto, desempenhar um decisivo papel.

\section{f) Aspectos de uma politica de carreira}

Esta politica deve ser abordada levando-se em consideração os seguintes aspectos:

Mercado de trabalho

A generalizada carência de mão-de-obra qualificada que se faz sentir tanto nos planos quantitativos como qualificativos, mas, principalmente, a măode-obra dotada de aptidões nos dominios da gestão e das técnicas, exige providências imediatas. Trata-se, principalmente nos países em desenvolvimento, de garantir o suprimento $e^{a}$ distribuição das mencionadas competências e aptidões, sem contudo abandoná-las inteiramente ao livre jogo do mercado de trabalho.

A despeito da freqüente precariedade institucional da administraçăo pública o suprimento das competências e aptidões, de uma mão-de-obra qualificada, é problema que não pode ser postergado. O Estado é compelido a estabelecer prioridades quanto às necessidiades que estão exigindo atendimento; a politica de carreiras orienta esta ação no sentido da prioridade a ser concedida às necessidades do setor público lato sensu. Dal resulta que a Administração Pública cuidará de ampliar o mais possivel o campo da seleção graças aos estímulos estabelecidos no quadro de uma politica global. As previsões dos efetivos ne- 
Cessários começam pelos setores quantificáveis (nos quais a aplicação de critérios quase-matemáticos para determinar os futuros efetivos revela-se Dossivel), empregando-se métodos analiticos em função do volume das atividades, das estruturas e das funções (por setores de atividade). A integração da assistência técnica em uma política global deste gênero deve, também, imPedir que inconscientemente esta assistência favoreça as evasões do mercado nacional de trabalho (brain drain) (CF. a discussão de novembro de 1968 ao ensejo da 23. ${ }^{a}$ Sessão da Assembléla Geral da ONU).

Informações

É evidente que uma politica de carreira carece de informação adequada no tocante ao pais, as estruturas de sua organização administrativa, a eficácia de seu sistema de ensino, a existência de uma política integrada de Pessoal, a amplitude e o papel do setor Privado, etc. A nova concepção da informação como arma do desenvolvimento, as sugestões relativas à criação do um pool internacional de informaŞão, constituem postulados a serem correlacionados com a introdução do critério de carreira e o desencadeamento desta política global.

Formação

E preciso recordar que uma correta abordagem do problema da ação formadora e modeladora no âmbito da função pública é condicionada pela politica de carreira; esta última estabelece uma conexão lógica entre a formação e o desenvolvimento da carreira; a falta dessa conexão reduz a eficácia recíproca. Cumpre examinar os liames existentes entre os empregos e as responsabilidades, a previsão das possiveis modificações da situação objetiva.

O aperfeiçoamento, setor da educação permanente, torna-se - nos parâmetros de uma politica global - uma etapa normal desta última; ele pode servir à verificação das aptidões atualizadas e tornadas necessárias pela outorga de novas responsabilidades; ele pode condicionar as promoções e justificar os registros de um cadastramento positivo.

O caráter profissional atribuído ao serviço na função pública valoriza, ao mesmo tempo, a natureza "profissionalizada" da formação e a influência que a profissionalização pode exercer sobre os programas de aperfeiçoamento e os métodos a utilizar. É, de resto, sob este ângulo, que as instituições especializadas das Nações Unidas propõem sistemas de carreira para determinadas categorias de agentes (UNESCO no tocante aos professores, B.I.T. aos inspetores do trabalho, etc.)

\section{Polivalência}

A polivalência para os quadros superiores de concepção e de comando na administração pública dos países em desenvolvimento, amplia a experiência dos respectivos funcionários nos setores e encargos mais variados, constituindo uma condição de orientação dos dirigentes para a abertura do espírito, rumo a uma visão de conjunto, para a rutura com o separativismo setorial (a tendência para a criação dos conhecidos feudos, domínios 
reservados, "little kingdoms"). Evitamse, assim, os exageros da especializaçăo, restringindo o campo de utilizaçăo razoável dos quadros e opondo-se à movimentaçăo, cujo papel na função pública se entremostra particularmente importante. Uma política de carreira permite eliminar 0 isolamento, psicológico e "técnico", das situações ocorrentes no serviço, e serve à movimentaçăo. As operaçŏes referentes admissão e designação para os empregos sucessivos não são entravadạs pela rigidez da organização administrakiva, mas partem da conciliação das consideraçōes empíricas ditadas pelas vicissitudes do serviço com uma politica previdente, e as mutáveis necessidades da administração pública.

\section{Participação}

A tendência para uma "participação" nos vários planos e em todos os niveis, concebida como um dos meios de aumentar a eficácia da Administração (Cf. Chi-Yuen-WU, op. cit. p. 148), é realizável graças a uma politica de carreira para cujo estabelecimento aconselha-se vincular o próprio pessoal.

A experiência comparada demonstra que essa participação, cujas formas mais adequadas urge pesquisar, Iigando-se às tradições próprias do país desempenha um papel psicológico de primeira categoria, limitando ou reduzindo o papel do "segredo" na ação administrativa que tende a se "demistificar" ou desmascarar, estimulando a melhor compreensão dos valores humanos, criando o clima de cooperação confiante. Ela se efetua simultaneamente no plano das relações do pessoal com o serviço, como no da Adminis- tração com os administrados. Ensinase, assim, ao pessoal administrativo a conhecer o verdadeiro sentido do EStado e alargar seu horizonte, praticando ao mesmo tempo uma melhor utilizaçăo das aptidöes, reduzindo-lhe a freqüente resistência às mudanças. Esta orientação parece corresponder perfeitamente às tendências de nossa época e à evolução futura das ideias. Para os países em desenvolvimento é certamente importante experimentar a aplicaçăo nesse plano das práticas administrativas comparadas, buscando novas situaçōes quanto às formas sutis de "autogestăo" nos negócios de pessoal e concebendo o serviço administrativo como um "processus" de permanente conciliação com o pessoal. Iniciar-se-ia, ao mesmo tempo, a necessária evolução da Administração pública no sentido de melhor se atualizar efetivamente servir, atingindo-se esse resultado tanto mais depressa quanto mais rapidamente evolua a sociedade.

\section{Personalidade dos funcionários}

Uma política de carreira, concebida desta forma, surge como poderoso instrumento de luta contra a "despersonalização" da funçăo pública, a ignorância e negligência da pessoa humana, assaz conhecidas na Administração burocrática do passado, dos países antigos, e condenados pela experiência. Nesta ordem de idéias tudo passaria a se fazer intuiti personae - levando-se na devida consideração os tipos de personalidade, o caráter de cada um, suas capacidades particulares. Năo săo as estruturas, mesmo as mais engenhosas, mas as iniciativas criadoras, a ins. piração e a ampla visão do pessoal bem selecionado e dispondo de ade- 
quadas perspectivas vitais, que podem assegurar o êxito da açãc. Seu dinamismo próprio deve ser apoiado pelas forças no poder e pela opinião pública. Uma política de carreira, criando efetivas possibilidades de promoção social para cada um (não somente as progressões nos graus hierárquicos e melhorias dos niveis de retribuição), e assegurando um adequado padrão material de vida durante e depois do serviço, corresponde, portanto, a uma necessidade e pode transformar uma massa amorfa de funcionários em um corpo dinâmico e prestigioso, apto a conduzir a bom termo a missão que the é especifica.

Elementos de uma "politique de carrière"

O recurso a uma política de carreira presume a existência de um sistema coerente de regras e de procedimentos se inserindo num quadro legal definido, compreendendo, entre outros, os seguintes elementos:

Seleção - Errada e freqüentemente identificada com a formaçäo preliminar (pre-entry training), e por vezes com o "estágio probatório", a seleção constitui uma fase inicial decisiva para a posterior trajetórią da carreira do funcionário. Operação freqüentemente conduzida de maneira primitiva e fortuita, e onde o favoritismo continua a se fazer sentir. Inútil desenvolver mais pormenorizadamente a idéia de que os niveis de qualidade da função pública dependem da seleção e dos métodos empregados, visando obter garantias de objetividade e a exclusão do arbitrário, (listas de aptidão, exames de entrada, concursos). Já não basta evitar, me- diante rigorosas provas seletivas, os erros mais clamorsos ("keeping the rascals out"), mas de escolher, com segurança, uma verdadeira elite intelectual, cujo valor humano e capacidade de trabalho estejam à altura da magnitude e importância de suas futuras responsabilidades e encargos. Um agregado de métodos modernos encontra-se atualmente à nossa disposição impondo-se, em face de sua evolução, uma abordagem prospectiva.

Recrutamento

Partindo de uma escolha preliminar, os organismos respectivos "recrutam" os candidatos. Este processo de recrutamento se modernizou altamente no Século $X X$ nos países desenvolvidos ("aggressive recruitment") e se liga estreitamente ao planejamento da mão-de-obra qualificada. Para os paises subdesenvolvidos, este processus desempenha um papel particularmente importante, como resulta das observaçōes anteriormente apresentadas. É ainda preciso que uma adequada infraestrutura exista e funcione imparcialmente para levar a cabo esta tarefa, que um equilibrio da pirâmide das idades seja respeitado e que o formalismo, sob todos os seus aspectos, seja escrupulosamente evitado.

Admissões

A carreira se desenrola através das sucessivas designaçōes para os cargos, funções ou empregos, o que exige, de imediato, um planejamento da utilização dos efetivos a médio e longo prazos, com a exclusão dos elementos do acaso e da improvisaçăo. 
A Administraçăo de Pessoal, reallzando uma verdadeira política de carreira. deve saber designar e aproveitar as pessoas em funçăo de suas aptidőes para exercer as respectivas atribuiçőes, e da previsăo do rendimento adequado, levando em conta a "entourage" imediata (adaptabilidade ao meio: superiores e camaradas de trabalho). Ela deve prever as futuras nomeaçöes levando em conta a necessária movimentaçăo de pessoal.

O respeito das vocações e a utilizaçăo planificada das capacidades e das especializações dependem disso.

A noçăo de "déroulement de carrière" se vincula portanto a essa cadela de sucessivas designaçōes para os empregos (a descrição de cada cargo - exata, na medida do possivel - e a definiçăo das respectivas responsabilidades săo indispensáveis, efetivamente correspondendo à prática de todos os sistemas da função pública, mesmo aqueles que não adotam a noçăo de "carrière"). Outros elementos da carreira que posteriormente se examinarăo (registros, situaçăo, condições, movimentação, aperfeiçoamento, remuneração) aparecem como instrumentos que possibilitam este cortejo de designações no interesse da utilização ótima da mão-de-obra, recrutada em função das provas iniciais determinantes da primeira nomeação (se for o caso) depois de um "post-entry training" na hipótese de ser o mesmo organizado).

Aperfeiçoamento

0 aperfelçoamento desempenha papel fundamental como garantia de re- ciclagem e atualizaçăo, - "rattrapage" (complemento da pre-entry education), a fim de atualizar as aptidões anteriormente adquiridas, de preparar os funcionários para o exercicio de novos encargos e tarefas, ou de adaptá-los às modificações das atuais incumbências e responsabilidades.

A modernização da Administração é Impensável sem este constante movimento para a eficácia na gestăo operacional do grande mecanismo público que cumpre manter em funcionmento, sempre atentando para as constantes mudanças e transformações econômico-sociais impostas pelo progresso científico e técnlco. São estreitas as relações que esse tipo de aperfelçoamento mantém com a pesquisa. Ao que parece, nos países em desenvolvimento ocorrem os cinco seguintes tipos de aperfeiçoamento de funcionários:

1) Aperfeiçoamento de adaptação visando adaptar o funcionário à sua formação, ou à que resulta de uma nova designação, e familiarizá-lo com o equipamento, levando em consideração as modificações deste último.

2) Aperfeiçoamento de manutençăo ou conservação - visando à atualização dos conhecimentos $e$ aptidర̃es anteriormente adquiridos.

3) Aperfeiçoamento de conversăo relacionado com as mudanças profisstonais exigindo a aquisiçăo de novas aptidões.

4) Aperfeiçđamento de evoluçăo tendendo a favorecer a mobilida- 
de na função pública para garantir mudanças previsiveis de designações.

5) Aperfeiçoamento de "rattrapage" - visando à recuperação e ampliação dos conhecimentos gerais dos funcionários cuja educação prévia parece insuficiente para o nivel do emprego que exerce.

As modalidades do aperfeiçoamento no cargo ou emprego durante a carreira $e$ o lugar em que for prestado podem ser diferentes ("in-service training" ou "out-service training", segundo o organismo interno ou externo, encarregado desta atividade. Seja como for, uma política razoável e coerente de aperfeiçoamento, cobrindo a totalidade da carreira, emanando da educação permanente, além de indisPensável, determina a estratégia das admissões. Nos países em desenvolvimento, o aperfeiçoamento ainda esporádico e fragmentário, năo leva suficientemente em conta o nivel dos funcionários admitidos. Afigura-se, portanto, essencial a repetição planificada dos ciclos de aperfeiçoamento, com estruturação e métodos pedagógicos adequados.

Registros

A avaliação da qualidade do trabalho de cada funcionário, comportando registros codificados e quantificados, sob a forma de relatório periódico, é uma das condições da evolução normal de sua carreira. Esta delicada operação oxige regras uniformes referentes à análise das qualidades intrínsecas correspondendo ao nível hierárquico, ao Caráter das relaçōes do funcionário com o público $e$ as responsabilidades ligadas à sua nomeação. A avaliação, conceito ou "nota", determina a promoção e permite apreciar a aptidão do titular de um determinado cargo, recolhendo na oportunidade da comunicação das menções os desiderata do interessado, considerados como uma das formas de participação. A fim de garantir a objetividade das mençōes, de que dependem a eficácia do sistema e o "moral" do pessoal, impöemse intruções sucintas quanto à aplicação dos métodos e da extensão do registro, bem como a desconcentraçăo da responsabilidade pelo cadastramento. A formação dos "notateurs" e o estabelecimento de uma escala de critérios respectivos parecem igualmente necessários, assim como o estabelecimento das diretrizes referentes à síntese dos registros periódicos e/ou especiais, do sério caráter dos registros, segundo princípios uniformes para toda a funçăo pública, quaisquer que sejam o "cloisonnement" e a compartimentaçăo dos órgãos.

\section{Movimentação}

O cuidado com a movimentação no desenvolvimento da carreira exige a possibilidade de proceder às alterações das admissões para impedir que o funcionário permaneça durante demasiado tempo - quiçá durante toda sua carreira - no mesmo cargo, funçăo ou emprego, e para beneficiar a administração com a multiplicação das experiências devidas às sucessivas dosignaçŏes no decorrer da carreira. A experiência dos paises mais adiantados evidencia uma tendência para garantir uma crescente mobilidade que se torna assim o traço característico 
de uma moderna política de carreira. Sem uma tal política, tais mudanças são dificeis ou impossiveis, o que impede a correta utilização das aptidöes e seu desenvolvimento.

\section{Promoção}

Uma correta política de promoção está no cerne da política de carreira. Em primeiro lugar dela dependem as perspectivas vitais que atraem os candidatos à função pública ou bloqueiam praticamente 0 acesso à esta última. A experiência comparada prova que o progressivo acesso às responsabilidades maiores constitui um elemento primordial, mais importante mesmo que o da remuneração. As promoções axofício ditadas unicamente pelo interesse do serviço, excluindo qualquer influência que não corresponda a este critério, podem ser efetuadas, por exemplo, depois, de acordo com os quadros elaborados, ou por outros métodos análogos, assegurando certas formas de participação dos interessados nestas operações. A combinação do sistema das promoçōes com o da mobilidade assegura um ritmo de promoções correto, a despeito da estreiteza dos compartimentos horizontais devidos ao fracionamento da funçăo pública. A objetividade da abordagem, ligada ao princípio da igualdade das oportunidades, qualquer que seja a distribuição dos efetivos entre unidades administrativas e entre graus hierárquicos, pode assegurar o desenvolvimento normal da carreira, sob condição da permanência dos contingentes de candidatos jovens que anualmente afluem ao serviço público $\theta$ do respeito pelas faixas etárias.

\section{Remuneraçẫo}

A coerência e homogeneidade do sistema de remuneração, geralmente ausente nos países em desenvolvimen to, são uma das causas do "nomadis" mo" administrativo, os funcionários pro" curando transferências e modificaçôes injustificadas pelas exigências do $\mathrm{sel}^{\mathrm{r}^{\circ}}$ viço, ou abandonando a administraçăo a fim de melhorar suas rendas. $\operatorname{Com}^{\circ}$ adequado manejo das carreiras $e^{r-}$ zoáveis retribuições pode-se, destarte, evitar o desperdício da experiência adquirida. As economias orçamentárias porventura evidenciadas revelam-se, na verdade, particularmente dispendiosas. Diversos problemas merecem ser resolvidos, nesta ordem de idéias, para garantir, do ponto de vista da remunera. ção, a evolução normal das carreiras cabendo observar: a igualdade das ${ }^{\mathrm{P}^{-}}$ tribuições das diversas categorias; ${ }^{a}$ uniformização dos critérios e padröes de retribuição (sem privilégios reservados a determinados serviços); a pre visão do automatismo das progressöes. escalas, niveis de remuneração das diversas categorias; o cuidado no sen- $^{n-}$ tido de assegurar eqüidade no tocante às remunerações dos contingentes de pessoal homólogo dos setores público. para-público e privado; a condenaçăa e repulsa do segredo que frequentemente envolve os problemas de retri buição. A política de indenizaçōes $e^{s^{-}}$ peciais, justificadas pelas circunstanclas especificas, não deve constituir uma rutura das paridades estabelecidas, nem destruir a estrutura $\theta$ hierarquia das retribuições, sob pena de ocasionar a degradaçăo de todo o sistema, e das repercussōes negativas sobre 0 desenvolvimento económico de que a função pública é um fator importante. 
Cabe sublinhar que, se a função pública nos países em desenvolvimento deve preencher lacunas da iniciativa privada, é preciso que o nivel dos funcionários, equitativamente remunerados, faça-os interlocutores válidos, sob Pena de que os quadros de valor, embora originariamente atraidos pelas perspectivas do serviço público se esforcem para dele sair, ou dele se evadam, no preciso momento em que os seus serviços parecem valiosos $e$ indispensáveis. Nos países economicamente pobres, a "fortaleza administrativa" não deve se desligar das massas populares, distanciando-se economicamente do nível médio destas últimas: isto Justifica uma relativa "austeridade". Esta contradiçăo, cujas repercussões podem ser graves, deve ser resolvida por meio de uma correta e cautelosa política de carreira.

Responsabilidade disciplinar

0 caráter profissional da função pública origina uma série de deveres Para os funcionários nos planos da imparcialidade, da legalidade e de uma lealdade específica para com o Estado, - o correto exercício das funções: trata-se do regime disciplinar. A participação dos interessados pode desemPenhar nesse regime um papel essencial que ultrapassa de muito as saņ̧ōes de naturezas proprlamente juridicas e abrange o domínio deontológico.

\section{Vantagens sociais e aposentadoria}

Um estimulo financeiro vinculado ao fim da carreira e incorporado às vantagens sociais é a garantia de uma aposentadoria, cujo princípio consiste em amparar o funcionário, na sua veIhice, pondo-o ao abrigo das necessidades materiais. A aposentadoria, geralmente calculada em função da retribuição global efetiva em proporção legalmente determinada, é devida à idade prevista pelos textos legais ao fim do serviço regular. Todos estes elementos são interdependentes e os liames entre eles existentes saltam aos olhos. Sua separação revela-se, afinal de contas, como uma cisão artificial de um conjunto cujos sucessivos estágios exigem sejam concebidos e analisados sob a ângulo de sua unidade fundamental plenamente valorizada pelo critério da "carrière".

Meios institucionais da administração do pessoal Generalidades

Durante muito tempo, apenas se percebeu a necessidade de uma infra-estrutura estável incumbida da gestão da função pública, tanto vale dizer, da administração geral, 3 quanto da gestão interna. 4 Efetivamente, a função pública aparecia como um fator menor e subalterno, quanto ao protagonismo ou seu papel no Estado.

Os primeiros esforços de reforma visaram, sobretudo, ao saneamento do ponto de vista da probidade, bem como à impugnação da arbitrariedade. Cogitava-se mais, no século $\mathrm{XIX}$, da luta contra a corrução sem ligar demasiada importância aos elementos objetivos da política de pessoal - um dos fundamentos dessas medidas.

Em conseqüência, se a noçăo do serviço administrativo do Estado evoluiu progressivamente no sentido do 
merit system o cuidado de assegurar o acesso das pessoas capazes e a eficácia do serviço não puderam ser garantidos por ausência de critérios objetivos para tal fim expressamente estabelecidos. $O$ único elemento de que se cogitava era o do recrutamento, fase inicial ou estágio inicial - todos os demais elementos (admissão, movimentação, promoção, etc...) havendo sido deixados de lado, marginalizados; quanto às modalidades de recrutamento, partia-se, o mais das vezes, dos modelos orientados segundo os exemplos do ensino superior.

Quanto aos outros estágios do serviço, procedia-se por meio de improvisações ou de empréstimos efetuados sem obediência a diretrizes gerais, de modelos freqüentemente peremptos, recorrendo-se, por vezes, a métodos totalmente obsoletos (désuètes). Os fatores sócio-psicológicos, e, sobretudo o elemento da motivação individual e coletiva, assim como a influência do ambiente (environnement, eco-sistema) eram fatalmente negligenciados.

Reunião dos dados

Os países em desenvolvimento ressentem-se cruelmente da ausência das informações básicas de que têm extrema necessidade, assim como dados estatísticos relativos a múltiplos problemas, dentre outros: a implantação do sistema da função pública; estimativa das necessidades - qualitativas $\theta$ quantitativas - em pessoal, da administração pública; os sistemas e técnicas para o recrutamento e a formação dos funcionários de todos os niveis; os problemas referentes às aptidöes exigidas no setor público, correlacionadas com o setor privado; o sistema de retribuição do pessoal; o custo real da função pública e sua distribuição; as modalidades de aperfeiçoamento etc. $\mathrm{Na}$ ausência de tais dados - a serem captados por meio de questionários e rigorosamente mantidos em dia - não é possivel elaborar um sistema de carreiras, cuja inspiração $e$ modelo devem ser determinados (V. Les Services Centraux...op. cit. p. 10, II). A coleta e armazenagem das informações indispensáveis devem, portanto, ser tidas como prioritárias.

Técnicas

Além da contribuiçăo de tais dados, cabe praticar certas técnicas a fim de adaptar o critério estabelecido às exigências específicas do país em apreço. Trata-se, neste sentido, de estudar a tecnicidade própria de uma política abrangente de carreiras compreendendo, em particular, o esforço de pleneJamento, de formação e da gestão. É neste sentido que, por exemplo, nos paises anglófonos prevê-se a atuação. dos Career Development Officers junto das Comissões do Serviço Público (OS DASP locais...) bem como organismos específicos de aperfeiçoamento administrativo; os projetos de aperfeicoamento dos futuros treinadores (training of trainers) prevêem a preparação ou formação de especialistas de formação, eles próprios formados para tal fim, o que - supondo-se realizado de maneira apropriada - poderia marcar uma modernização da obra de aperfeiçoamento com relação aos $\mathrm{mo}^{-}$ delos existentes. Vários métodos tendem a realizar uma modernização administrativa, corrente e a longo prazo, 
das carreiras, e todo projeto tendendo a desenvolver os métodos, as técnicas $\theta$ os procedimentos referentes à gestão dos negócios de pessoal na administração pública deveria, no interesse de assegurar sua eficácia, ser vinculado aos estudos da política de carreira e do regime de gestão da função pública.

Órgãos

Uma politica de carreira não é possível se faltam serviços de pessoal incumbidos da realização desta política $\theta$ devidamente equipados e localizados na hierarquia administrativa.

A experiência demonstra a necessidade de tais serviços centrais planificadores, promotores, coordenadores, catalizadores e controladores das resPectivas ações. A tendência à criação de tais órgãos ou serviços é geral, no mundo de nossa época, quaisquer que sejam os modelos adotados, sejam, por exemplo, serviços de estadomaior, encarregados da execução geral das medidas relativas à administração pública e tendo, em primeiro lugar, Uma missão consultiva consoante o "exemplo francês; ou, ao contrário, uma "super-direção" do pessoal correspondendo às tendências britânicas (Projeto Fulton de 1968), quer seja ela unitária e colegiada, conforme o modelo dos Estados Unidos da América do Norte, ou pluralista e distribuida entre um órgão colegiado e um outro freqüentemente hierarquizado (Les Services Centraux...op. cit., pp. 35 e sgts). Estes serviços de pessoal são freqüentemento ou quase sempre incumbidos de arranjos menores no domínio dos assuntos correntes de pessoal, e por vezes, mesmo, do equipamento material de "bureau", ao invés do estabelecimento e realização de uma verdadeira política do emprego público, de uma "política de pessoal". São, por vezes, supercentralizados e, conseqüentemente, isolados dos serviços "ministeriais" ocupando-se, também, de uma série de operações relativas aos assuntos de pessoal. Uma centralização à outrance e uma rígida separação dos demais órgãos administrativos centrais ameaçam criar uma situação em que se planeja no vácuo e onde a atuação do serviço central especializado, sem laços estabelecidos com outros serviços e com o mundo exterior, pode, de antemão, condenar a política em questão. Os estudos tendo como finalidade o exame crítico das estruturas, da organização, da localização na hierarquia, do papel e da missão dos órgãos centrais da administração de pessoal nos países em desenvolvimento devem, portanto, ser estreitamente integrados com os concernentes à política de carreira e devem, em particular, compreender a análise dos problemas essenciais, a saber:

I) Caráter e amplitude da missão supra-departamental do órgão central de gestão, em particular no concernente à sua competência na tomada de decisões.

II) Especialização profissional de seu pessoal e existência de aperfeiçoamento neste sentido.

III) Participação do pessoal interessado na gestão de seus negócios, modalidades e maneiras de ser desta participação. 
IV) Distribuição das funções, no quadro da administração do pessoal, entre este serviço supra-departamental e outros órgãos.

V) Natureza das relaçōes do mencionado serviço com os outros órgãos centrais e periféricos.

VI) Natureza de tais relações com o exterior (em particular com as instituições de ensino).

vii) Existência nos níveis inferiores da hierarquia de órgãos subordinados ao serviço supra-departamental da administração do pessoal.

\section{III - NOTAS}

1) Ocorrendo o perigo de mal-entendido ou equívocos semânticos, - exato sentido do critério de "carreira" merece ser esclarecido: Etimologicamente corresponde à idéia do movimento no decorrer do periodo durante o qual um cargo ou emprego é exercido; trata-se, por conseguinte - como se afirmou - de um processo dinâmico, de passagens sucessivas de um estágio do serviço para outro. Logicamente este critério parte de uma concepção de continuidade do serviço, ao contrário de um engaJamento provisório, temporário, exercido esporádica ou intermitentemente, ou a título secundário, - por exemplo, acumulando-o com outros encargos, tarefas, atribuições, fora da função pública. Psicologicamente valori- za-se, no caso, a idéla da vocação inicial para a função pública, a dedicação ao serviço. Do ponto de vista sócio-econômico impöese considerar o fator do engajamento a título profissional, o que situa o problema em uma dimensão peculiar, presume uma formação especifica, consoante a educação geral, e se vincula a um aperfeiçoamento periódico decorrente da educação permanente como segmento da educaçăo dos adultos. Surgem, destarte, responsabilidades profissionais de ordem deontológica, com rejeição das concepçöes do amadorismo e da improvisação da formaçẵo profissional rotineira. Er: ora năo se trate de uma inevitável poculiaridade do referido critéric - $10-$ vado ao extremo -, ele corresponde a um serviço profissional permanente, quiçá um engajamento para vida inteira, na hipótese em que as modalidades estatutárias e da gestăo dos problemas do pessoal administrativo possibilitarem a manutenção da vocação do funcionário, assegurando-lhe condições morais e materiais que o condicionem.

2) A educação de um trabalhador competente constitul, dentre todos, o mais dispendioso investimento, sobrecarregando, pesadamente, a economia nacional. A titulo de llustraçăo pode-se citar P.F. Drucker (The Effective Executive, New York, 1967, p. 5) segundo o qual a educaçăo de um Ph.D. em ciências naturais custa, por exemplo, nos Estados Unidos, cerca de 100.000 a 
200.000 dólares em capital social; a de um diplomado num "college" custa, aproximadamente, 50.000 dólares. Para os países pobres este fardo é praticamente insuportável; o desperdicio das competências, sejam quais forem, deve, portanto, ser evitado a qualquer preço. $O$ cálculo do custo da formação de um administrador qualificado ainda não foi efetuado; provavelmente, o aludido custo é bastante alto. $O$ alto custo evidenciado pelos citados exemplos bastaria para justificar o estabelecimento de condições capazes de garantir uma razoável amortização dessas despesas.

3) "Conjunto das medidas tomadas pelo governo, ou pelos serviços centrais da função pública, com a finalidade de gerir os cargos ou empregos em relação $\mathrm{com}$ as necessidades nacionais em mão-de-obra, as diretrizes da política econômica, financeira e social do Estado, e a neceśsidade de prover a administração, de imediato ou no futuro, de um pessoal competente e qualificado".

4) "Tratamento do conjunto dos problemas da administração do pessoal em serviço desde o início até o fim dos vínculos"; administração corrente do pessoal e conjunto de medidas quotidianas. Cf. in Les Services Centraux... op. cit., p. 9).

5) FORMAÇÃO: "Pode-se definir a formação no seu sentido mais geral, como uma transformação do indivíduo (aquisição de conhecimentos, adoção de atitudes ou aprendizagem de gestos), determinada pela transmissão de novos conteúdos de pensamento, de novos principios de julgamento ou de novas maneiras de agir" P.H. Giscard, in "La Formation et le Perfectionnement du personnel d'encadrement", apud Jacques Ardoino, "Management ou Commandement, Participation et Contestation", Paris, 1970, Fayard-Mame.) FORMAÇÃO E APERFEIÇOAMENTO: "Entre formação $e$ aperfeiçoamento cabe estabelecer uma certa distinção, ao menos de principios: a formação é o desenvolvimento de capacidades novas, enquanto que o aperfeiçoamento é a melhoria das capacidades em exercício. A formação $e$ o aperfeiçoamento do pessoal constituem processos de desenvolvimento das capacidades, dos conhecimentos das aptidões e atitudes (Op. cit.) 
